\title{
O SENTIDO DAS TEORIAS PEDAGÓGICAS NO ENSINO DA ARTE EM ESCOLAS DO CAMPO: DIÁLOGO ENTRE PAULO FREIRE E ANA MAE BARBOSA
}

DOI: $10.48075 /$ RI.V24I2.26093

Fernanda Monteiro Barreto Camargo ${ }^{1}$ Marina Rodrigues Miranda²

RESUMO: Analisa a relação do ensino da arte na Educação do Campo a partir das contribuições do pensamento de Freire para os estudos sobre educação e a Abordagem Triangular de Ana Mae Barbosa, tendo como referência as teorias pedagógicas da educação e a concepção da arte como construção, conhecimento e produção do sujeito. A questão surge a partir da necessidade de se discutir como se constitui o ensino da Arte nas escolas do Campo e seus diversos sujeitos e culturas. A análise das concepções pedagógicas e das teorias de ensino da arte mostra que ainda precisamos avançar, abdicando do ideário eurocêntrico, de forma a romper com as dialéticas tradicionais que invisibilizam saber e culturas. $\mathrm{O}$ artigo pretende cooperar para a disseminação de reflexões acerca do ensino da arte na educação do campo.

\section{THE MEANING OF PEDAGOGICAL THEORIES IN THE TEACHING OF ART IN THE SCHOOLS OF THE: DIALOGUE BETWEEN PAULO FREIRE AND ANA MAE BARBOSA}

\footnotetext{
${ }^{1}$ Pós Doutora, Doutora e Mestre em Educação pela Universidade Federal do Espírito Santo (UFES). Especialista em Gestão Escolar, Liderança do 3o Setor e Mediação em EaD pela UFES. Graduada em Educação Artística, Artes Plásticas (UFES) e Pedagogia. Professora do Departamento de Linguagens, Cultura e Educação - Centro de Educação (UFES). Líder o Grupo de Pesquisa Imagem, Tecnologia e Infâncias (GEPITI), pesquisadora do Observatório da Formação de professores de Artes na América Latina e membro do NUPEEES - UFSB. Desenvolve projetos nas áreas de Formação de Professores em Artes, Culturas e Leitura de imagem.: fmbcamargo@gmail.com

2 Professora Especialista em Orientação Acadêmica em EAD pela universidade Federal do Mato Grosso (UFMT); Especialista em Educação Física Escolar pela Universidade Federal do Espírito Santo, Mestrado em Educação pela Universidade Federal do Espírito Santo (2007) e Doutorado em Educação pela Universidade Federal da Bahia (2013). Professora Adjunto - Nível I da Universidade Federal do Sul da Bahia/UFSB; Atuo na Pósgraduação em Agroecologia e Educação do Campo da Universidade Federal do Sul da Bahia/UFSB; Líder do Núcleo de Pesquisa, Ensino e Extensão em Experiência do Sensível na linha de Estudos e Pesquisas com Crianças, atuando principalmente nos seguintes temas de estudos e pesquisas: Educação de Infâncias quilombolas e indígena; Membro do grupo de Pesquisa Imagens e Tecnologias e Infâncias. marina.miranda@ufsb.edu.br
} 
ABSTRACT: It analyzes the relation of the teaching of Arts in the countryside based on the pedagogical theories of education taking as reference the Triangular Proposal of Ana Mae Barbosa and its conception of Arts as a tool of construction, knowledge and production of the subject. The question arises in the need to discuss how the teaching of Arts constitutes in the schools of the Countryside and its various subjects and cultures. The analysis of pedagogical conceptions of Arts teaching theories shows that we still need to move forward by giving up the Eurocentric ideas in order to break with traditional dialectics that invisibilize knowledge and cultures. The article intends to cooperate in the dissemination of reflections on the teaching of Arts in the education in the countryside.

Key Words: Countryside Education; Art Teaching; Pedagogical theories.

\section{INTRODUÇÃO}

Atuar no campo da educação é mover-se em favor do comprometimento social, reverberando-se numa prática de humanização imbricada em responsabilidade social e ética, tudo isso incorporado aos fatores históricos, sociais e culturais que orientam as decisões da legislação sobre educação.

Diante disso, para compreender as teorias pedagógicas, segundo Ferraz e Fusari (2009), é preciso, antes de tudo, contextualizar sócio-política-filosoficamente e dialogar com a relação ensino-aprendizagem. Mormente, é imperativo que se façam escolhas pedagógicas a fim de deliberar sobre princípios, objetivos, justificativas, métodos e, mormente, sobre o posicionamento de não neutralidade, tão vívido atualmente, frente aos contextos e questões nos quais os sujeitos estão inseridos.

Em conformidade com Freire $(1990 ; 1981 ; 2001)$, que nos incita para o discurso de não neutralidade, ensinar e aprender são parte constitutiva do ser humano, uma ação permanente e, por isso, ao mesmo tempo é razão e consciência, pois, segundo o autor, temos vocação para humanização, apesar de constantemente sermos desafiados a uma desumanização. Tal processo de humanização só faz sentido a partir de uma análise concreta da realidade, com palavras grávidas de mundo (Freire,2001, p. 29), sendo necessário notarmos que, no fazer pedagógico, estão contidos objetivos políticos, morais e ideológicos em virtude de sua natureza complexa e dialética .

Outrossim, segundo Freire(2008), educamos para autonomia, integração social e apropriação de saberes .São esses aspectos que orientam o fazer pedagógico, suas teorias 
e/ou perspectivas, remetendo-o a uma dimensão político-social que precisa ser considerada no âmago de tal fazer.(Freire,1996;).

Em uma análise feita pelo viés da Sociologia da Educação, Andrade; Ferreira (2009) dizem que desde Durkheim, no século XIX, a educação sempre foi usada como instrumento de estabilidade social e que isso reverbera-se, até hoje, em práticas de educadores do século $X X$ e nas tendências pedagógicas. No Brasil, tal cenário não foi diferente. Segundo Simões (2009) , foi somente a partir da década de 1990, sob uma enorme pressão social e por meio de movimentos e políticas de inclusão, observou-se o aparecimento de novos atores sociais, que passaram a participar da ação pública e ocupar lugares, anteriormente, destinados às elites.

Um desses movimentos insere-se a Educação do Campo como uma modalidade de ensino, suscitada de exigências dos movimentos sociais brasileiros, conforme explicam Lima; Costa; Pereira (2017), e arrazoada em contraposição a uma educação bancária, tradicional, europeia e capitalista, que adota uma posição etnocêntrica e, sobretudo, que se impôs como modelo necessário do desenvolvimento histórico, legitimando e justificando, primeiro, a colonização e, depois, o imperialismo, que tanto desvalorizou culturas populares em favor de si mesma. Segundo Chauí (2005), tal modelo de educação não compreende cultura como imperativo social, "A lei humana é um imperativo social que organiza toda a vida dos indivíduos e da comunidade, determinando o modo como são criados os costumes, como são transmitidos de geração em geração, como fundam as instituições sociais (religião, família, formas de trabalho, guerra e paz, distribuição de tarefas, formas de poder etc.)" (CHAUI, 2005, p.52).

Daí a importância de compreender a epistemologia das tendências pedagógicas a partir da liberdade e o comprometimento do educador. Tal comprometimento se alcatifa como base para práticas de docência . Segundo Freire:

Como o acrescentamento que o homem faz ao mundo que não fez. A cultura como resultado do seu trabalho, do seu esforço criador e recriador. O sentido transcendental de suas relações. A dimensão humanista da cultura. A cultura como aquisição sistemática da experiência humana, como uma incorporação por isso crítica e criadora, e não como justaposição de informes ou prescrições doadas. (FREIRE, 1996, p. 121).

Neste artigo, como opção metodológica, dispomos as tendências pedagógicas em dois eixos: no primeiro, a Tendência Liberal, que marcou as práticas educacionais 
brasileiras nos últimos 50 anos e, quiçá, vem ocupando lugar no cenário atual, vide os recentes ataques contra educação pública, de qualidade e gratuita. Mostrando-se ora conservadora, ora renovada, preparando os indivíduos para os papéis sociais de acordo com as aptidões individuais. Um exemplo mais recente disso é a Lei 13.415 , que trata do Novo Ensino Médio e das competências e habilidades que precisam ser apreendidas para que os indivíduos se adaptem aos valores e às normas vigentes na sociedade hegemônica , tais medidas, embora propaguem a ideia de igualdade de oportunidades, não consideram a desigualdade de condições, falta-lhes equidade, e agravada em tempos de pandemia com o advento do Ensino a Distância e atividades remotas . No segundo, a Tendência Progressista, que representa os objetivos sócio-políticos da Educação, que se posicionam, em seus tempos/espaços, na contramão de uma sociedade liberal e neoliberal, como um instrumento de luta e resistência dos professores, no mover-se contra hegemônico.

O referencial metodológico parte da análise de conteúdo, tendo como objeto as tendências pedagógicas estabelecidas no Brasil desde o início da década de 20 até as atuais propostas de desmantelamento da educação pública e, ainda, da análise das Leis de Diretrizes e Bases da Educação de 1961, 1971 e 1996, das interlocuções com Barbosa ( 1984; 1997; 1998; 2001; 2002; 2003;2017) e com Freire (1992; 1996; 2001; 2005; 2008; 2010; 2011). Buscando o dialogismo, conceito bakhtiniano no qual os sentidos dialógicos da verdade se caracterizam pela ideia oposta ao modelo de conhecimento monológico. Por meio da interação entre pessoas que a procuram coletivamente, construímos o texto com várias vozes, a fim de constituirmos um enunciado que ganhasse sentido para os leitores.

\section{CAMPO EPISTEMOLÓGICO DAS TENDÊNCIAS PEDAGÓGICAS COMO DETERMINANTE DE PRÁTICAS EDUCATIVAS EM ARTE}

Autores como Ferraz e Fusari (2009), lavelberg(2008), Barbosa(2001; 2002; 2003) vêm contextualizando a educação em arte a partir da história da educação, e o fazem utilizando como referência as duas grandes tendências que orientam as práticas pedagógicas no Brasil, a Tendência Idealista Liberal da qual fazem parte a: Pedagogia Tradicional, Pedagogia Nova e Pedagogia Tecnicista e a Tendência Realista Progressiva integrada pela: Pedagogia Libertadora, Pedagogia libertária e Pedagogia Histórico Crítica. Tais pedagogias consideram o processo de ensino-aprendizagem ora na dimensão humana, ora 
na dimensão político-social e ora na dimensão técnica, aplicando, nesse processo de ensinar aprender, conhecimentos para resolver problemas.

Conforme já indicado no início do texto, a Tendência Idealista Liberal se constitui como uma orientadora de práticas pedagógicas que vão do tradicional ao tecnicismo e que, nos últimos 50 anos, tentam preparar o indivíduo para desempenhar um bom papel social, leia-se por bom como adequando-se às demandas dos mercados liberais e neoliberais, bem como às culturas hegemônicas, desconsiderando a desigualdade de condições entre os sujeitos.

A ação dessa tendência no ensino da arte tem relação com as práticas de Educação Artística e suas práticas de reprodução, ilustração e laisse-faire, além da estética mimética ligada às cópias do natural e à repetição de modelos reprodutivistas, nos quais se valorizavam desenhos de ornatos, geométricos e decorativos. Metodologicamente, os professores encaminhavam os conteúdos através da Lei de Diretrizes e Bases da Educação4042/61 e sua concepção humanística e positiva, que instituiu o ensino de Artes nos níveis de 1으 e 2 o graus da Educação Básica.

Art. 38, inciso IV do Capítulo I, Título VII. Título VII Da Educação de Grau Médio. Art. $38 \mathrm{Na}$ organização do ensino do grau médio serão observadas as seguintes normas: IV Atividades complementares de iniciação artística (LDB Lei no 4.024/61)

Ou seja, o ensino de Artes era ministrado de forma optativa, obedecendo às normas para o ensino de 2ำ grau como prática educativa artística ou útil. Dez anos mais tarde, promulga-se a Lei de Diretrizes e Bases no 5.692/71, que passa a tratar o Ensino da Arte com um caráter tecnicista, com o nome de Educação Artística,

Art. 70 Será obrigatória a inclusão de Educação Moral e Cívica, Educação Física, Educação Artística e Programas de Saúde nos currículos plenos dos estabelecimentos de ㅇo e 2 을 graus, observado quanto à primeira o disposto no Decreto-Lei n. 369, de 12 de setembro de 1969. (LDBE/71 Lei $n$ - 5.692 de 11 de agosto de 1971)

Segundo Ferraz Fusari; (2009), nessa época, o ensino da arte era considerado uma não matéria, sem contornos fixos, flutuando por onde as tendências o levassem.

Tal fragilidade reverberou em ações pedagógicas frágeis, sem definição metodológica, conteudista e organizada de forma aleatória. Os professores eram polivalentes, formados 
em cursos de Licenciatura em Educação Artística de Curta Duração, com duração de dois anos para ensinar no 1 을 grau e de quatro anos para ensinar no 20 grau, a fim de atender a uma demanda imposta pelo mercado

Tentando minimizar as divergências conceituais, o Ministério da Educação fez parcerias com a Escolinha de Arte e, em 1977, criou o Programa de Desenvolvimento Integrado de Arte Educação (PRODIARTE). Segundo Barbosa,

\begin{abstract}
Seu objetivo era integrar a cultura da comunidade com a escola, estabelecendo convênios com órgãos estaduais e universidades. Nosinícios de 1979, 17 unidades da Federação tinham iniciado a execução de projetos ligados ao PRODIARTE. Em muitos casos dominou o populismo. Os programas de maior consistência foram os levados a efeito entre 1978 nos Estados da Paraíba (convênio com a Universidade Federal da Paraíba e Secretaria de Educação), Rio Grande do Sul (convênio com DAC-SEC) e Rio de Janeiro (convênio com Escolinha de Arte do Brasil e SEC-RJ) (BARBOSA,2003, p.13 )
\end{abstract}

A criação da PRODIARTE só fez crescer a urgência de instrumentos de resistência no grupo de arte educadores. Socialmente, vivia-se, no país, um momento de intensa ação dos movimentos sociais e políticos, que ganhavam força por meio das centrais sindicais, organizações não governamentais, associação de profissionais da educação e cultura, que mostravam desde a carência em algumas áreas quanto a força de ação dos grupos organizados.

Diante do momento de conturbação social, movido pela ação crítica, surge a Tendência Realista Progressista, que parte da análise crítica das realidades sociais que sustentam as finalidades sociopolíticas da educação. Dela advêm: a Pedagogia Libertadora, que se propõe a criticar e questionar as relações do homem com seu meio, o conteúdo é organizado a partir dos temas geradores e tem um engajamento para sua libertação, a aprendizagem se dá pelo envolvimento dos sujeitos no processo de construção. A Pedagogia Libertária, atribui à escola o papel de transformar o estudante no sentido libertário para participação ativa na sociedade. Segundo Barbosa (2017), a Arte/educação tem se caracterizado como campo de conhecimento, durante a sua trajetória histórico-sócio-epistemológica vem agregando diferentes estudos, frutos de pesquisa científicas, produções, experiências com o ensino da arte nos espaços escolares e extraescolares. 
Dessa forma, nas tendências críticas, a arte é concebida como conhecimento e - ao contrário do que ocorre nas teses liberais, positivistas e modernistas - defende-se a ideia da arte na educação com ênfase na própria arte. Portanto, compreender a arte como uma área de conhecimento, como uma construção social, histórica e cultural é trazer a arte para o domínio da cognição. Nessa direção, o conceito de arte também está ligado à cognição como um dos elementos de manifestação da razão, pois existe na arte um conhecimento estruturador, que permite a potencialização da cognição. (Barbosa, 1997).

No Brasil tem-se visto que a tendência de relacionar o ensino da Arte apenas a cognição tem provocado pensamento sobre como se ensina arte, segundo Barbosa (1998) preocupação compartilhada por Pillar (1999) quando nos provoca a explicar o processo de ensino-aprendizagem dos conhecimentos artísticos não mais por meio de técnica ou expressão, mas por meio de um contemplar de obras e de um olhar para as relações do sujeito com a arte, segundo a autora, essa ressignificação de paradigmas nasce da concepção crítica de ensino de arte.

Em 1988, com a promulgação da Constituição Brasileira e com ela a Lei de Diretrizes e Bases da Educação no 9394/96, organizações de classe iniciaram um longo processo de resistência e reconhecimento do ensino da arte para formação do estudante e inspirados por Ana Mae e suas colaboradoras pensaram o que seria denominada Proposta Triangular de Ensino de Arte. Segundo Barbosa (1998,p. 45),

\begin{abstract}
Essa proposta deriva de uma dupla triangulação. [...] ao designar os componentes do ensino/aprendizagem por três ações mentalmente e sensorialmente básicas que são: criação (fazer artístico), leitura da obra de arte e contextualização. A educação cultural que se pretende com tal proposta é uma educação crítica do conhecimento construído pelo próprio aluno com a mediação do professor, acerca do mundo visual, e não, uma educação bancária. Ao contrário da concepção de ensino como técnica que valoriza o produto artístico em detrimento do processo e da concepção de ensino de arte como expressão que supervaloriza o processo, dando pouca importância ao produto estético, a concepção de arte como conhecimento vem buscando a valorização tanto do produto artístico, como dos processos desencadeados no ensino de arte, trazendo para o contexto atual da Arte/Educação a ideia de arte como processo e produto (BARBOSA,2017,p. 45)
\end{abstract}

A partir dos estudos de Barbosa (2001), Pillar (1999), Martins; Picosque; Guerra (1998;2008;) e Hernandez (2000) é possível compreender o ensino da arte como multi, inter e transcultural, e as relações de alteridade para aprendizagem dos conhecimentos artísticos 
a partir da interrelação entre o fazer, o ler e o contextualizar a arte, em diálogo com princípiosformativos da Educação doCampo encontrados no pensamento de Freire $(1987,2001)$, possibilitando compreender os diferentes termos tais como multiculturalismo, pluriculturalismo e interculturalismo, que, na atualidade, aparecem como sinônimos no ensino de Arte.

\section{PENSAMENTO FREIRIANO E OS PRINCÍPIOS DA EDUCAÇÃO DO CAMPO PARA ENSINO DA} ARTE

Se nos atentarmos ao pensamento freiriano $(1982 ; 1984 ; 2005 ; 2008)$, encontraremos nele princípios da Educação do Campo, especialmente, quando descreve o homem como ser social e consciente, que busca transformar a sociedade por meio da educação. Da mesma forma, corroborando com ele, Arroyo; Caldart; Molina (2008) dizem que é preciso lutar pelo que identificam como uma luta pelo direito de educação para todos, pelos sujeitos da educação do campo, pelos sujeitos do campo, por uma educação do campo que se faça vinculada às lutas sociais do campo, contra a desumanização. A educação do campo se faz no diálogo com os diferentes e necessita da construção de um projeto educativo que reafirme a finalidade da ação educativa, combinando o fazer no campo com a pedagogia, ou seja, significa estudar e viver no campo, dessa forma, as educadoras e educadores têm um conceito mais amplo de educar, no qual o trabalho principal são o de fazer e o de pensar a formação humana.

Logo, pensar em Educação do Campo é pensar na formação integral do sujeito, no desenvolvimento sustentável, no coletivo e na alternância. Segundo Simões; Franco;Salim (2009), por longos períodos da história da Educação no Brasil, o ensino-aprendizagem não era pensado vinculado aos saberes, às culturas e aos fazeres dos sujeitos, com isso, existia uma educação desconexa do homem e de suas origens.

Assim, sujeitos do campo eram levados a um desgostar-se do seu lugar, viviam marginalizados, excluídos, abandonados, invisibilizados em suas manifestações culturais. Não se pensavam ações para as diversidades culturais. Somente, após grandes lutas populares, a educação libertadora de Freire (2011, p.32), cujo pensamento é que "ninguém liberta ninguém, ninguém se liberta sozinho". Os homens se libertam em comunhão ganha um sentido de busca da própria identidade, que paradoxalmente, movido 
pelo autoritarismo da ditadura, acabou por se mostrar um movimento de resistência como ato político.

Resistencia que nos possibilita, segundo Freire (1987), pensar sobre desumanização do homem, que comprar "fractais" do tempo do homem, segundo Berardi (2019) até que os oprimidos tomem consciência das razões de seu estado de opressão e deixem de aceitar fatalistamente a sua exploração, movendo-se contra ao regime opressor.

Somente quando os oprimidos descobrem, nitidamente, o opressor, e se engajam na luta organizada por sua libertação, começam a crer em si mesmos, superando, assim, sua convivência com o regime opressor. Se esta descoberta não pode ser feita em nível puramente intelectual, mas da ação, o que nos parece fundamental é que esta não se cinja a mero ativismo, mas esteja associada a sério empenho de reflexão, para que seja práxis. (FREIRE, 1987, p.72)

Assim a ação política é uma ação cultural e libertadora, a arte ocupa esse lugar de ação para liberdade, fruto de reflexão acerca de quem são os sujeitos do campo, sejam comunidades quilombolas, ribeirinhas, indígenas, pequenos agricultores ou os marginalizados de toda sociedade, negros, mulheres, crianças, minorias sociais, de forma que rompa com a ideia de dependência para criar mais dependência. Não obstante, uma ação libertadora, nunca fecha os olhos as necessidades dos vulneráveis , mas atenta-se a transformação, reflexão e ação.

Este é um esforço que cabe realizar, não apenas na metodologia da investigação temática que advogamos, mas, também, na educação problematizadora que defendemos. O esforço de propor aos indivíduos dimensões significativas de sua realidade, cuja análise crítica lhes possibilite reconhecer a interação de suas partes. (FREIRE, 1987, p. 133)

Não cabe aqui o olhar de Alice para País das Maravilhas, que teimosa, viveu sem tempo em um lugar que não era real. Vivemos tempos reais, onde não encontraremos pílulas de crescer ou encolher ou quem sabe Coelho Branco ou Gato Risonho, nosso papel enquanto educador é provocar indignação frente as realidade postas como verdades absolutas,, contra a autoritarismo insano que não dialoga com docentes e discente.

Segundo Dussel, o sujeito negado, o sujeitado, a vítima que não pode viver (2002, p.15). Que, sem cair no vitimismo, constrói o próprio projeto de vida, narra a própria história e afirma a própria alteridade, não por violência, mas por conscientização. Contudo não 
bastava permanecer apenas na conscientização. Era necessário desenvolver a liberdade positiva, libertar-se para reconstruir a sociedade, democratizar direitos e assumir a direção política, passar da condição de subjugação para subjetivação pelo fenômeno catártico (promovido para o Gramsci).

Ensinar e aprender é uma constante investigação, porém adverte para que não torne o homem, nesse processo, um mero objeto de investigação para que não se perca a essência do ser humano. Começaremos reafirmando que os homens são seres das práxis. São seres do querer fazer, diferentes, por isso mesmo, dos animais, seres de o puro fazer. Os animais não admiram o mundo, imergem nele. Os homens, pelo contrário, como seres do querer fazer emergem dele e, objetivando-o, podem conhecê-lo e transformá-lo com seu trabalho. (FREIRE,

1987,

É nesse momento que as práticas pedagógicas libertadora e libertária passam a fazer sentido na educação do Campo. A Educação como instrumento de transformação social, de transformação gestacional. Conteúdos são definidos não mais por um currículo pensado para as elites ou para os oprimidos, mas pensado nas relações horizontais de aprendizagem, nas quais o tema surge a partir do interesse do grupo.

Nos fundamentos da educação do campo está a construção do sujeito, pois escola e trabalho sempre caminharam juntos, apesar de Gramsci $(1968$, p.130) dizer que a escola, mediante o que ensina, luta contra o folclore, contra todas as sedimentações tradicionais de concepções de mundo, convergindo para discussões para as culturas, os saberes-fazeres, os tempos-espaços das comunidades, as territorialidades, as falas, as matrizes culturais locais, a arte popular.

É pensar na arte-educação pelo viés da cultura, pois por ela fugimos da concepção tradicional, mas ao mesmo tempo nutrimos esteticamente, segundo Picosque e Martins (1998).

Onde a cultura passa a ser o fator determinante e a arte passa a ser então um canal de emancipação, como fez com Jacotot, personagem de Jacques Ranciere (2011). A arte como artefato de transformação social, como pratica educativa, uma vez que além de todo o mencionado anteriormente, também é fundamental que o espaço de traduz a postura do professor crítico-reflexivo, ou seja, do professor que busca um processo de ensino-aprendizagem contextualizado, que considere a análise investigativa e que reflita sobre a própria prática, porque esta também é conhecimento. 
Os arte/educadores do campo são mediadores culturais, no sentido do estar entre: estar entre o artista e observador, no olhar e na escuta, para gerar questões que apenas têm sentido se provocam a reflexão, a conversação, a troca entre os parceiros. Um estar entre que precisa ser mais apurado. Martins; Picosque, Guerra (2008). Como exemplo, temos a Escola de Ensino Fundamental Assentamento União de Conceição da Barra, apresentada por Irineu Gonçalves Pereira, surgida a partir da primeira ocupação do ES, em 1985, com cerca de 87 famílias e que se vincula ao modo de vida do campo existente no Espírito Santo, evidencia a comunidade como protagonista de propostas educativas, o que fortalece a ideia de que os direitos assegurados na lei só se concretizam quando a população se mobiliza para lutar por eles. Segundo Pereira (2013, p.123) “A articulação das escolas do campo colocou o tema Educação do Campo em destaque na sociedade.

Dentre alguns projetos da escola estão: Arte, com realizações de oficinas Projeto Arte com vida e Projeto Recriarte, que trabalham com artes plásticas, teatro e música na escola a partir dos saberes/fazeres de sua comunidade.

Precisamos revisitar um conceito de arte, que se oriente pela arte popular e erudita sem peso maior oumenor. Reconhecer as diferenças culturais e os conceitos de multiculturalismo, interculturalismo, trans culturalismo. Compreender que não existem culturas puras, mas culturas híbridas e uma diversidade de produção artística.

A Educação do Campo precisa ser pensada como um espaço de educação heterogêneo, flexível e participativo. $O$ ensino da arte precisa promover reflexão, autoestima, pertencimento, empoderamento na perspectiva intercultural, precisa ser um ensino que promova interação de diferentes culturas, suas vivencias e seus diálogos, sem perder de vista a luta pelos direitos dos sujeitos do campo por uma vida digna, direito de serem valorizados, respeitados e reconhecidos culturalmente.

E, por fim, que se realizem práticas participativas e dialógicas para que os arte/ educadores, nesse contexto, sejam verdadeiramente Arte/ Educadores do Campo

\section{CONCLUSÃO}

É fato que desde a década de 70 o ensino da arte vem se constituindo como mote de discussões acadêmicas, e, de certo modo, com abundância na literatura educacional, talvez 
isso se deva ao fato de um amplo movimento em favor da institucionalização da Arte /Educação que de fato constitui a arte como ensino.

Segundo Barbosa (2001), a Arte/educação tem se caracterizado como campo de conhecimento, durante a sua trajetória histórica-sócio-epistemológica vem agregando diferentes estudos, frutos de pesquisa científicas, produções e experiências ao ensino da arte nos espaços escolares e extraescolares.

Ferraz e Fusari( 2010) reforçam que fatores sócio culturais são determinantes para que as concepções de ensino da arte se manifestem, dentre eles, estão o comprometimento do ensino artístico com a industrialização século 19, a vinda da família real ao Brasil, a Semana de Arte de 22, os princípios do liberalismo e da experimentação psicológica século 20, a LDB 4024/61 prática educativa e atividade complementar de iniciação artística , LDB 5692/71 educação artística, Anos 80 movimentos de arte educadores, novas concepções estéticas e tendências da arte contemporânea, LDB 9294/96 - arte com componente curricular obrigatório, entre outros.. Segundo Martins, Picosque; Guerra (1998) , Fazer Arte é produzir sentido

Sentido designado por Barbosa (1998, p. 35) como os componentes do ensino/aprendizagem por três ações: criação (fazer artístico), leitura da obra de arte e contextualização.

As mudanças de paradigma no ensino da arte, numa concepção contemporânea, levam-nos a questionar o conhecimento dos grandes mestres dos períodos clássicos da arte, e alguns artistas do modernismo brasileiro e a exclusão das diferentes culturas, como indígena, africana e popular, assim como as propostas artísticas contemporâneas, Logo , as teorias críticas e pós-críticas podem nos ajudar em tais reflexões, sobre a Arte como um artefato social e cultural, caracterizado pelas relações de poder que o constituem são resultado de uma escolha num universo amplo de conhecimentos e saberes.

Como salienta Silva (2001, p.16), por que esse conhecimento e não outro? Quais interesses fazem com que esse conhecimento e não outro esteja no currículo? Por que privilegiar um determinado tipo de identidade ou subjetividade e não outro? Ao selecionar os conteúdos e privilegiar um tipo de conhecimento de arte, os professores exercem uma relação de poder, determinando também uma concepção de arte. 
O ensino da arte numa forma inter-multi-pluricultural. Nesse sentido, deve questionar a concepção de arte modernista que supervaloriza o novo e impõe uma estética ocidental, dita universalista,

Picosque, Martins e Guerra (2008) tratam da arte desde o conceito de mediação cultural, chegando a sugestões para o professor -propositor em ações de mediação dentro dos espaços educativos. Pensar em arte dentro e fora do espaço escolar, valendo-se de uma atitude investigativa, inquieta e curiosa. A triagem traduz em si as escolhas do professor e deve provocar no aluno uma experiência estética, pois somente quando vivese a significação se tornam uma só coisa. Isso fica evidenciado quando se percebe os modos de presença da arte e o papel do sujeito contemplador de arte para aquele fruidor, receptor, participante, operador.

Nesse sentido, os saberes do professor mediador importam, porém, podem ser completados com os encontros de um com o outro. Segundo Pareyson (2001), entre um dos infinitos aspectos da forma e um dos infinitos pontos de vista da pessoa. Ou seja, das multiplicidades de leituras possíveis e a inesgotabilidade da arte como realidade vista pela diversidade de suas leituras, contaminados pelo cultural, pelos discursos dominantes e marginais.

Ser mediador é encontrar brechas de acesso, tangenciando assim os desejos, interesses e necessidades dos aprendizes, é preciso pensar nos desafios instigadores e estéticos, com comentários estimulantes e sem respostas obvias.

É preciso propiciar espaços de recriação da obra, instigar combinações, facilitar o encontro entre a arte e o fruidor, pensando na ação específica como uma área singular e percebê-la como canal de comunicação, estudando o processo, atentando para os ruídos perturbadores e para exclusão de aspectos que poderiam tornar o encontro mais significativo. Uma mediação provocativa ao invés de informativa.

Segundo Barbosa (2001), é preciso inter-relacionar curadoria, pesquisa e arteeducação, estabelecendo ações a partir de cada evento, pois todos têm a responsabilidade de facilitar a comunicação e a apreciação do público. Em sala de aula, todos esses interlocutores se conectam e só experimentam quando a experiência estética envolve a cognição, afeto e vida.

Concluímos dizendo que necessitamos da arte horizontalmente, em todas as disciplinas: português, biologia, química, matemática, história, geografia, mas também 
necessitamos da arte verticalmente, como um conteúdo específico, que leva à reflexão e ao aprofundamento sobre aprendizagem, pois o que se aprende em arte é transferível para outras áreas .

Por isso, a tentativa dos arte-educadores em estabelecer uma forma de diálogo com a cultura norte-americana e europeia, e não uma submissão. Nesse sentido, como movimento de resistência, foi criado, em 1984, o Conselho Latino-Americano de Educação pela Arte, uma tentativa da América Latina se estabelecer na Sociedade internacional de ensino da arte. Afinal, arte para que? Arte para consolar, arte para inebriar, arte para sentirse acolhido, arte para conhecer, arte para viver.

\section{REFERÊNCIAS}

ARROYO, Miguel; CALDART, Rosali; MOLINA, Mônica. Por uma educação do campo. 3a ed. Rio de Janeiro: Vozes, 2008.

BARBOSA, Ana Mae. História da Arte-Educação. (org.) São Paulo: Max Limonad, 1984.

BARBOSA, Ana Mae. Arte-Educação: leitura no subsolo. São Paulo: Cortez,1997.

BARBOSA, Ana Mae. Tópicos Utópicos. Belo Horizonte: Com/Arte, 1998

BARBOSA, Ana Mae. (org.). Arte/Educação contemporânea: consonâncias internacionais. São Paulo: Cortez, 2001.

BARBOSA, Ana Mae. Inquietações e mudanças no ensino da Arte. São Paulo: Cortez, 2002.

BARBOSA, Ana Mae. Arte Educação no Brasil: do modernismo ao pós-modernismo. REVISTA Art\& - Número 0 - Outubro de 2003

BARBOSA, Ana Mae. Redesenhando o desenho. São Paulo: Cortez, 2017

CHAUI, Marilena. Natureza, cultura, patrimônio ambiental. In: Comissão de Patrimônio Cultural da USP, Meio Ambiente: patrimônio cultural da USP. São Paulo: Edusp/Imprensa Oficial, 2005.

FERRAZ, Maria Helena; FUSARI, Maria. Metodologia do Ensino de Arte: fundamentos e proposições .2a ed. São Paulo: Cortez, 2009.

FREIRE, Paulo. Conscientização. São Paulo: Cortez \& Moraes, 1981. 
FREIRE, Paulo. Pedagogia da autonomia: saberes necessários à prática educativa. 23. ed. São Paulo: Paz e Terra, 1996.

FREIRE, Paulo. Política e Educação: ensaios. 5 ed. São Paulo: Cortez, 2001. (Coleção Questões de nossa época; v.23)

FREIRE, Paulo. Pedagogia do oprimido. 28. ed. Rio de Janeiro: Paz e Terra, 2005.

FREIRE, Paulo. Pedagogia do compromisso. São Paulo: Vila das Letras, 2008.

FREIRE, Paulo. À sombra desta mangueira. 6. ed. São Paulo: Olho d'Água, 2010.

FREIRE, Paulo. A importância do ato de ler: em três artigos que se completam. 51. ed. São Paulo: Cortez, 2011.

GRAMSCl, Antônio. Os Intelectuais e a Organização da Cultura. Rio de Janeiro: Civilização Brasileira, 1968.

HERNANDEZ, Fernando. Cultura Visual Mudança Educativa e Projeto de Trabalho. Porto Alegre: Artmed, 2000

IAVELBERG, Rosa. Para gostar de aprender arte: sala de aula e formação de professores. Porto Alegre: Artmed, 2008

LIMA Maria Aires de; COSTA, Frederico Jorge Ferreira; PEREIRA, Karla Raphaella (2017). Educação do Campo, Organização Escolar e Currículo: um olhar sobre a singularidade do campo brasileiro e Curriculum, 2017.

MARTINS, Mirian Celeste; PICOSQUE, Gisa; GUERRA, Maria Terezinha Telles. Didática do Ensino da Arte: a língua do mundo: poetizar, fruir e conhecer a arte. São Paulo: FTD, 1998.

MARTINS, Mirian Celeste; PICOSQUE, Gisa; GUERRA, Maria Terezinha Telles. Mediação cultural para professores andarilhos na cultura. Rio de Janeiro: Instituto Sangari, 2008.

PAREYSON, Luigi. Os problemas da estética. 4ạ ed. São Paulo: Martins Fontes; 2001.

PILLAR, Analice (org). A educação do olhar. Porto Alegre: Mediação, 1999.

RANCIERE, Jaques. O mestre ignorante. Belo Horizonte: Autêntica, 2011

SIMÕES, Regina Helena Silva; SALIM, Maria Alayde Alcantara (orgs). História da Educação do Espírito Santo: vestígios de uma construção. Vitória: EDUFES, 2009.

Recebido em 15 de outubro de 2020.

Aprovado em 28 de janeiro de 2021.

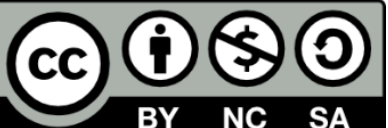

